\title{
Sequências Tipológicas em Artigos de Opinião no Contexto de Vestibular
}

\author{
Opinion Articles Tipologic Sequences in Vestibular Entrance \\ EXAMS CONTEXT
}

Adair Vieira GONÇALVES*
Maria Tocie Ishizaki HIGA**

Resumo: O objetivo deste artigo é apresentar resultados de análise de sequências tipológicas explicativas e argumentativas, consideradas como essencialmente dialógicas, a partir de uma proposta de escrita do gênero artigo de opinião. Os textos foram produzidos por candidatos ao Curso de Letras durante o processo seletivo vestibular da Universidade Federal da Grande Dourados-UFGD. O aporte teórico-metodológico utilizado foi o interacionismo sociodiscursivo (ISD) e o seu modelo de análise de textos (BRONCKART, 2003). Os resultados apontaram para uma incidência maior de sequências argumentativas, consideradas como favorecedoras de potencial argumentativo, em contraposição ao uso reduzido de sequências explicativas, usadas parcialmente pelos vestibulandos.

Palavras-chave: Interacionismo Sociodiscursivo. Gêneros textuais. Sequências tipológicas.

Abstract: The objective of this article is to present the results of analysis in argumentative and explanatory sequences, considered as essentialy dialogical, extracted from opinion articles. The texts were written by the candidates for Letter Course of Grande Dourados Federal University admittance examination. The research was based on the theory of Sociodiscursive

* Docente da Universidade Federal da Grande Dourados. Agradeço ao CNPq pela Bolsa de Produtividade em pesquisa, processo no 302720/2011-1. Agradecemos também aos Professores Jean-Paul Bronckart (UNIGE), Elvira Lopes Nascimento (UEL) e Eliana Merlin Deganutti de Barros (UENP) pelas leituras atentas em versões anteriores deste texto. Contato: adairgoncalves@uol.com.br.

** Mestre em Linguística Aplicada pela Universidade Federal da Grande Dourados. Contato:marhiga@gmail.com. 
Interactionism (ISD) and the its text analysis model (BRONCKART, 2003). The results pointed out a major number of complete argumentative sequences, which may be considered as favorable of greater argumentative power in contrary of reduced explanatory sequences used partialyby the candidates. Key-words: Socialdiscursive Interacionism. Textual genre. Sequences typological.

\section{Introdução}

Este artigo apresenta parte dos resultados de uma pesquisa empreendida no âmbito do grupo Gêneros Textuais e Formação de Professores cadastrada na base de dados do CNPq. O estudo apresenta uma análise das sequências tipológicas explicativas e argumentativas, mais frequentes no gênero em foco, de um corpus de produções escritas do gênero Artigo de Opinião, coletadas junto ao Centro de Seleção da Universidade Federal da Grande Dourados - UFGD, de candidatos concorrentes ao curso de Letras.

O objetivo desta pesquisa é analisar a infraestrutura textual, especificamente a planificação sequencial do texto utilizada pelos candidatos no momento de produção escrita; ou seja, verificar como os estudantes organizam as sequências tipológicas para atingirem seu intuito comunicativo: obtenção de vaga numa universidade pública federal ao empreender uma ação linguageira pela qual será expresso o posicionamento sobre o tema proposto pela comissão organizadora da prova, qual seja: os valores da belez̧a ao longo da história e sua relação com os valores vigentes na sociedade neste início de século XXI. Para efetivar a análise, nos apoiamos nos pressupostos teóricos e metodológicos do Interacionismo Sociodiscursivo (ISD) e no modelo para análise de textos propostos por Bronckart (2003).

\section{O Interacionismo Sociodiscursivo (ISD) e seu Projeto Teórico- Metodológico Básico}

O ISD, vasta corrente teórica contemporânea, contesta a divisão/ separação das ciências em ciências humanas e ciências sociais. Por isso, esse aporte teórico-metodológico deseja ser compreendido como ciência do humano (BRONCKART, 2006). Bronckart e o grupo de pesquisadores 
genebrinos apoiam-se no construto de Vygotsky (1998), procurando reunificar a Psicologia atribuindo-lhe uma dimensão social. Contudo, como afirma Machado (2007), não se pode dizer que o ISD seja uma teoria da Psicologia ou da Linguística, pois sendo constitutivamente transdisciplinar, o não pode ser confinado a nenhum desses quadros disciplinares de forma estanque.

A principal ideia defendida pelo grupo é a de que o desenvolvimento dos indivíduos ocorre em atividades sociais, em um meio constituído e organizado por diferentes pré-construídos e através de processos de mediação, sobretudo os linguageiros. Com isso, desde seu nascimento, os indivíduos podem ir se apropriando desses pré-construídos sociais, permitindo seu desenvolvimento e, dialeticamente contribuindo para a transformação permanente dos pré-construídos.

O interesse maior de pesquisa de Bronckart e de sua equipe é o estudo do desenvolvimento humano mediado pela linguagem. O ISD volta-se para o estudo dos discursos e dos textos, acrescentando ao termo interacionismo o adjunto sociodiscursivo, já que "a emergência das formações sociais e a diversificação das atividades práticas estão intrinsecamente ligadas à emergência de atividades de linguagem, em um processo de negociação com o contexto em que elas se realizam" (BARROS, 2012, p. 35). Estudar a linguagem sociodiscursivamente significa não apenas tentar elaborar um modelo das condições de produção do texto e de sua organização, mas, sobretudo, compreender as ações humanas e as interações sociais. É uma tentativa de estudar as produções verbais a partir da interdependência existente entre as propriedades dos textos e do contexto não verbal.

Tal abordagem teórico-metodológica procura analisar as mediações formativas por meio das quais os pré-construídos sociais da história humana são apropriados pelos indivíduos (seja por meio de atividades gerais, seja por atividades linguageiras), num processo dinâmico e permanente, que, consequentemente, vai transformar a sociedade e esses mesmos indivíduos (BRONCKART, 2006).

Decorrente das influências epistemológicas de Bakhtin/Volochinov (1997), Bronckart (2003) defende que a organização social dos seres humanos é extremamente complexa e diversificada e, em todos os grupos humanos, a linguagem, oral ou escrita, figura como o instrumento semiótico de excelência de interação entre os pares.

No Brasil, os pesquisadores, em vez de apenas corroborarem as pesquisas europeias, validam (BARROS, 2012) e ampliam as ferramentas 
teórico-metodológicas do ISD (NASCIMENTO, 2011). Tomando como ponto de ancoragem as sequências didáticas desenvolvidas em Genebra, as pesquisas em solo brasileiro, dentre outras adaptações ao modelo teóricometodológico do ISD, utilizam, por exemplo, as "noções de capacidades e operações para a construção de modelo didático de gêneros ${ }^{1}$ e para a avaliação de materiais didáticos e das capacidades de linguagem dos alunos na produção e na leitura de textos" (MACHADO, 2009, p. 36-37), além de construir listas de controle/constatações para controle da textualidade para além das apresentadas pelo grupo europeu (GONÇALVES, 2007).

Em seu aparato teórico-metodológico para análise de textos, Bronckart (2003) explicita que estes são constituídos por três camadas superpostas, denominadas de folhado textual: a infraestrutura geral do texto, os mecanismos de textualização e os mecanismos enunciativos ${ }^{2}$. A infraestrutura global divide-se em plano geral do texto, tipos de discurso e de sequências; os mecanismos de textualização, por sua vez, são divididos em conexão, coesão nominal e coesão verbal; os mecanismos enunciativos são constituídos pelas modalizações e vozes. Associando esse aparato (folhado textual) à abordagem didática para o ensino de línguas da Universidade de Genebra, temos: i) capacidades de ação - implicam as representações do meio físico e da interação comunicativa, por isso, de natureza sociossubjetiva, neste caso, em situação de vestibular; b) capacidades discursivas - relativas à infraestrutura supracitadas; c) capacidades linguístico-discursivas - implicam os mecanismos de textualização (operações de conexão, coesão nominal e verbal), os mecanismos enunciativos (distribuição das vozes, a escolha das modalizações) e a escolha lexical e sintática ${ }^{3}$ (GONÇALVES; BARROS, 2010).

${ }^{1}$ O modelo didático, denominação da ferramenta semiótica teórico-metodológica defendida pelo Grupo de Genebra tem o objetivo de subsidiar o trabalho docente e favorecer o ensino/aprendizagem da leitura/produção/de textos, além de tornar visíveis as dimensões ensináveis de determinado gênero, a partir das quais diversas sequências didáticas podem ser concebidas. O modelo deve abarcar as três capacidades de linguagem a serem desenvolvidas: capacidades de ação, discursivas e linguísticodiscursivas.

${ }^{2}$ Remetemos o leitor a Bronckart (2003) a Atividade de linguagem, textos e discursos: por um interacionismo sociodiscursivo para aprofundamento nesta perspectiva teórica.

${ }^{3}$ Sobre esses procedimentos, consultar Bronckart (2003). 
Decorrente de tal procedimento didático, o vestibulando, ao empreender uma ação de linguagem, "reúne e integra os parâmetros do contexto de produção e do conteúdo temático, tais como um determinado agente os mobiliza, quando empreende uma intervenção" (BRONCKART, 2003, p. 99). Então, descrever uma ação de linguagem consiste em identificar a valoração atribuída por este agente-produtor, neste caso, estudante em situação de vestibular, aos parâmetros do contexto, e aos elementos declarativos do conteúdo a ser tematizado num texto.

Esta mesma ação de linguagem resultou textos empíricos diferentes, já que tal ação "não é um sistema de restrições, mas uma base de orientação a partir da qual o agente-produtor deve tomar um conjunto de decisões". Outra questão teórica importante é a do empréstimo ao arquitexto ${ }^{4}$. Por outro lado, ao fazer tal utilização, o agente-produtor pode modificar e adaptar sua produção escrita, ainda que circunscrito a uma situação de vestibular, à evolução comunicativa que os gêneros podem sofrer ao longo dos tempos e aos seus valores pessoais (estilo) ${ }^{5}$.

Todo texto é resultado de um ato realizado num contexto físico, pelas coordenadas espaço-temporais em que ocorre uma determinada ação linguageira. Bronckart (2003) cita o lugar físico e o momento da produção, além do emissor (pessoa física que produz o gênero artigo de opinião) e o receptor (pessoa física que recebe o texto). Mas a produção de qualquer texto está associada às atividades de uma formação social, implicando o mundo social e, consequentemente, seus valores e contratos, são, pois, “as normas, valores, regras sociais, etc., assim como a imagem que o agente faz de si e do destinatário ao agir - implicados no quadro de uma forma de interação comunicativa” (BARROS, 2012, p. 86). A seguir, um quadro que sintetiza dos dois contextos de produção.

${ }^{4}$ Os gêneros de textos encontram-se disponíveis no arquitexto, que é o conjunto de gêneros já elaborados pelas gerações precedentes, que podem/devem ser utilizados pelos agentes-produtores de hoje.

${ }^{5}$ Não é nosso objetivo neste texto analisar as transgressões ou utilizações particulares do gênero, mas tão somente analisar as sequencialidades materializadas na superfície textual. 


\begin{tabular}{|c|c|c|}
\hline $\begin{array}{c}\text { Parâmetros do } \\
\text { Contexto de Produção } \\
\text { do Gênero Artigo de } \\
\text { Opinião }\end{array}$ & Na Esfera jornalística & $\begin{array}{l}\text { Na Esfera universitária, } \\
\text { em contexto de seleção }\end{array}$ \\
\hline Lugar social de produção & $\begin{array}{c}\text { Numa instituição } \\
\text { jornalística, por exemplo. }\end{array}$ & $\begin{array}{l}\text { Numa sala de aula onde } \\
\text { foi realizado o processo } \\
\text { seletivo. }\end{array}$ \\
\hline $\begin{array}{l}\text { Enunciador (papel social } \\
\text { do emissor) }\end{array}$ & $\begin{array}{l}\text { Jornalista ou pessoas } \\
\text { convidadas a produzir } \\
\text { artigos opinativos a } \\
\text { respeito de uma temática } \\
\text { de sua especialidade. }\end{array}$ & $\begin{array}{c}\text { Estudante que objetiva } \\
\text { uma vaga no curso de } \\
\text { Letras da UFGD. }\end{array}$ \\
\hline $\begin{array}{c}\text { Destinatário (papel social } \\
\text { do receptor) }\end{array}$ & $\begin{array}{l}\text { Dirigido ao público leitor } \\
\text { do jornal do jornal, } \\
\text { interessado no tema, seja } \\
\text { para apoiar ou recusar a } \\
\text { tese defendida. }\end{array}$ & $\begin{array}{c}\text { Pessoa social - } \\
\text { Constituída por uma } \\
\text { banca de professores } \\
\text { formados em letras, cujo } \\
\text { objetivo é, a partir de } \\
\text { uma grade de avaliação, } \\
\text { classificar estudantes para } \\
\text { frequentarem cursos de } \\
\text { graduação na UFGD. }\end{array}$ \\
\hline Objetivo da interação & $\begin{array}{l}\text { Provocar a reflexão sobre } \\
\text { o tema e conduzir à } \\
\text { tomada de } \\
\text { consciência/decisão/opin } \\
\text { ião; }\end{array}$ & $\begin{array}{l}\text { Produzir o gênero artigo } \\
\text { de opinião, com o } \\
\text { propósito de ser avaliado } \\
\text { positivamente e, desse } \\
\text { modo, poder ter acesso à } \\
\text { Universidade. }\end{array}$ \\
\hline Circulação & $\begin{array}{l}\text { Irrestrita, em tempos de } \\
\text { Internet. }\end{array}$ & $\begin{array}{l}\text { Folha oficial para a } \\
\text { produção do texto. }\end{array}$ \\
\hline
\end{tabular}

Quadro 1 - Contexto de produção do gênero

É necessário alertar, entretanto, que o contexto de produção e o texto empírico não mantêm entre si uma relação mecânica, mas sim uma base de orientação ("situação de ação interiorizada", no dizer de Bronckart, 2003, p. 92) a partir da qual os vestibulandos produzem artigos de opinião ${ }^{6}$. A partir

${ }^{6}$ Em situação de vestibular, como sabemos, não é dado ao candidato, a partir do contexto de produção, tomar a decisão de qual gênero utilizará para a produção do texto, já que, no processo seletivo da UFGD, na proposta de escrita, comum a todos os candidatos, é oferecido apenas o gênero artigo de opinião como base orientativa. 
dessa base, vamos analisar as representações dos candidatos às restrições do gênero e do conteúdo temático, mais especificamente em relação às sequências tipológicas argumentativa e explicativa, já que estas são as mais frequentes neste gênero, como atestam as pesquisas de Gonçalves (2007) e Gonçalves e Barros (2010).

\subsection{Sequências tipológicas argumentativas e explicativas e seu estatuto dialógico}

Para esta pesquisa, delimitamos a análise às sequências tipológicas do gênero artigo de opinião. A organização sequencial ou linear do conteúdo temático é parte importante da infraestrutura textual. Bronckart (2003) retoma o sentido de macroestrutura, conhecimento internalizado na memória do produtor do texto, de forma lógica e hierárquica, para explicar o funcionamento da organização sequencial do discurso em forma de enunciados.

Quando da (re-)semiotização do pensamento em um texto, devido às restrições técnicas da produção verbal humana, esses conhecimentos tornam-se, necessariamente, objeto de uma reorganização, inserindo-se em estruturas sintáticas básicas (relações predicativas e/ou sintagmas) que são, por sua vez, organizadas no eixo do sucessivo. As macroestruturas disponíveis simultaneamente na memória desenvolvem-se, pois, em diversas formas de organização linear (planos, esquemas, sequências, etc.) que, às vezes, têm sido denominadas de superestruturas textuais (BRONCKART, 2003, p. 217).

Bronckart baseia-se em Adam para a abordagem dos tipos de sequências, mas amplia a proposta defendida por este autor. Além das cinco sequências básicas defendidas por Adam - narrativa, descritiva, dialogal, argumentativa e explicativa -, Bronckart apresenta os scripts e esquematizações ${ }^{7}$, observáveis em textos empíricos. Tais sequências e scripts são diferentes

${ }^{7}$ Para ampliação dessas discussões, remetemos o leitor ao capítulo 6 da obra Atividades de linguagem, textos e discursos: por um interacionismo sociodiscursivo (BRONCKART, 2003). 
formas de planificação que se combinam nos textos. Para Bronckart, (2003, p. 219),

Essas diferentes seqüências podem ser combinadas em um texto, em várias modalidades (encaixamento hierárquico, mesclas, etc.) e é da diversidade das seqüências e da diversidade de suas modalidades de articulação que decorre a heterogeneidade composicional.

Nos textos empíricos, as sequências tipológicas concretizam-se em tipos linguísticos variados, podendo ser realizados em todas as macroproposições que definem a sequência ou em apenas algumas delas. Além disso, pode haver múltiplas formas de encaixamento das macroproposições, contanto que a estrutura hierárquica do conjunto da sequência seja preservada.

Faz-se necessário trazer também à discussão o estatuto dialógico das sequências tipológicas. Para Bronckart (2003, p. 233), as tipologias, na verdade, são "apenas construtos teóricos, elaborados secundariamente a partir do exame das seqüências empiricamente observáveis nos textos”. Segundo o autor, essas sequências podem servir de parâmetro para o agente-produtor, mas apenas como uma espécie de generalizações das práticas sociais de linguagem, indexadas num arquitexto, mas "não procedem, pois, de uma competência textual biologicamente fundada” (p. 233). Apoiando-nos ainda em Bronckart (2003, p. 234), as formas como os indivíduos reorganizam as sequências num determinado gênero é

[...] motivada pelas representações que esse agente tem das propriedades dos destinatários de seu texto, assim como do efeito que deseja produzir. O empréstimo de um protótipo de seqüência, disponível no intertexto, resulta, portanto, de uma decisão do agente-produtor, orientada por suas representações sobre os destinatários e sobre o fim que persegue. $\mathrm{Na}$ medida em que se baseiam nessas decisões interativas têm um estatuto fundamentalmente dialógico.

Quando o produtor de texto tem diante de si um objeto controverso/ polêmico, tende a organizar tal objeto em uma sequência argumentativa. $\mathrm{O}$ raciocínio argumentativo implica, em primeiro lugar, a existência de uma 
tese, supostamente admitida e não necessariamente impressa, a respeito de um tema. Sobre essa tese são propostos argumentos que são objetos de um processo de inferência que é orientadora de nova conclusão ou tese. Já o contra-argumento é uma nova proposta para contra-atacar a tese apresentada anteriormente. Trata-se de um recurso valioso para convencer o leitor a concordar com o ponto de vista defendido pelo autor, pois permite comparar e aferir de modo mais democrático um tema sob dois pontos de vistas diferentes. No quadro do processo de inferência, esse movimento argumentativo pode ser apoiado por algumas justificações ou suportes, mas pode também ser moderado por restrições.

A semiotização desse raciocínio argumentativo em um segmento de texto, geralmente, economiza a exposição da tese anterior (pressuposta) e só concretiza o processo de inferência por meio dos diferentes tipos de suportes e restrições explicitados. Assim, o protótipo da sequência argumentativa, segundo Bronckart (2003), apresenta quatro fases:1) fase de premissas (tese) em que se propõe uma constatação de partida; 2) fase de apresentação de argumentos, isto é, de elementos que orientam para uma conclusão provável, podendo ser esses elementos apoiados por lugares comuns, regras gerais, exemplos, etc.; 3) fase de apresentação de contra-argumentos, que operam uma restrição em relação à orientação argumentativa e que podem ser apoiados ou refutados por lugares comuns, exemplos, etc.; 4) fase de conclusão (ou de nova tese) que integra os efeitos dos argumentos e contra-argumentos.

Esse modelo pode ser realizado de modo simplificado: passar diretamente da premissa à conclusão ou dos argumentos à conclusão, deixando implícitas as outras fases do protótipo. Mas pode também ser realizado de modo mais complexo: explicitação da tese anterior, entrelaçamento dos argumentos e dos contra-argumentos, etc. Especificamente em relação à sequência argumentativa, o agente-produtor (vestibulando que deseja uma vaga num determinado curso, neste caso), quando faz uso desse "modelo" de macroproposição, toma um objeto do discurso (a questão da beleza, já definido pela equipe elaboradora do processo seletivo vestibular). Tendo o contexto de produção sociossubjetivo (neste caso, uma banca de professores-corretores de textos com formação em Letras) e com este objeto discursivo de natureza controversa, "lança mão" de uma tese, a ser fundamentada por recursos retóricos de argumentação, refutação, negociação. 
Em relação à sequência explicativa, esta se origina da representação de um fenômeno tido como incontestável. Como essa constatação inicial apresenta-se incompleta ${ }^{8}$, necessita-se explicar as contradições aparentes que poderia suscitar. Esse desenvolvimento é realizado por um agente autorizado e legítimo que explicita as causas e as razões da afirmação inicial, assim como as das questões e contradições que essa afirmação suscita. No fim desse desenvolvimento, a constatação inicial encontra-se reformulada e, geralmente, enriquecida.

Esse raciocínio explicativo apresenta-se sob a forma de uma sequência bastante simples cujo protótipo compõe-se de quatro fases (BRONCKART, 2003): 1) fase de constatação inicial, que introduz um fenômeno não contestável (objeto, situação, ação); 2) fase de problematização, em que é explicitada uma questão da ordem do porquê ou do como, eventualmente associada a um enunciado de contradição aparente; 3) fase de resolução (ou de explicação propriamente dita), que introduz os elementos de informações suplementares capazes de responder às questões colocadas; 4) fase de conclusão-avaliação, que reformula e completa eventualmente a constatação inicial.

Em relação à sequência explicativa, o agente-produtor pode considerar que seu discurso pode ser compreendido como problemático pelo destinatário (BRONCKART, 2003). Decorre desse "problema" a natureza dialógica da sequência explicativa e de sua frequência no gênero". Bronckart (2003) defende o estatuto dialógico das sequências tipológicas, defendendo

${ }^{8}$ Apesar da denominação completa/parcial, sabemos que elas estão completas e/ou parciais em relação ao modelo prototípico, não significando, entretanto, que a sequência parcial seja defeituosa ou algo afim. Significam apenas formas reduzidas de planificação decorrente da representação dos agentes-produtores no momento da interação.

${ }^{9}$ Não desconsideramos, como defende Bronckart (2003, p. 250), "que todo texto é necessariamente composto por tipos de discurso, baseados em operações constitutivas dos mundos discursivos...". Para o autor, "as sequências só aparecem como manifestações de operações suplementares, de caráter ideológico". Ainda que seja secundada pelos tipos de discurso, nosso objetivo aqui reside na investigação das formas de planificação do conteúdo temático mobilizadas pelo agente-produtor, no momento de produção de um texto, em situação adversa: em contexto de vestibular. $\mathrm{O}$ autor ainda defende e, para mais aprofundamento remetemos o leitor à obra clássica de 1999, que as sequências tipológicas estão associadas aos mundos do Expor e do Narrar. 
que o agente-produtor toma emprestado um protótipo disponível no arquitexto, de acordo com as representações que o produtor tem de seu destinatário. Além disso, a dialogicidade das sequências prototípicas ocorre porque o conteúdo temático estocado na memória do produtor, na forma de macroestruturas, precisa ser desdobrado sintaticamente, isto é, é necessário desenvolver as fases dentro de uma língua natural, no nosso caso, o português.

Conforme já explicitado na definição das sequências tipológicas, quando o enunciador julga que o interlocutor não vai entender determinado objeto do discurso, utiliza o recurso da sequência explicativa. Entendemos que essa dialogicidade ocorre mesmo nos casos de sequências incompletas, com a ausência de uma ou de duas fases, já que no processo de uma sequência tipológica, o autor tem a liberdade de ser mais específico, com a opção de chamar a atenção para determinado tema, problematizar, resolver e avaliar ou deixar algumas dessas fases para o interlocutor complementar/imaginar. Por outro lado, quando isso ocorre (ausência de algumas fases), creditamos tal fato a duas hipóteses: a ausência de atividades orais e escritas referentes ao desenvolvimento de capacidades de ação, ou seja, o estudante apresenta dificuldade em fazer a representação do contexto físico e, principalmente, sociossubjetivo (cf. NIÉRI, 2011); e as dificuldades relativas à argumentação propriamente dita (PÉCORA, 1999).

\section{Metodologia}

Para a consecução da pesquisa, apoiamo-nos nos pressupostos da pesquisa qualitativa, de abordagem interpretativista. Para Bortoni-Ricardo (2008), sob esse ponto de vista, não há como observar o mundo independentemente das práticas sociais e dos significados vigentes. Para Flick (2004), nesta abordagem metodológica, constitui papel importante a reflexividade do pesquisador sobre as ações e observações; neste caso, reflexões sobre as ações de linguagem empreendidas por candidatos ao curso de Letras de uma instituição federal de ensino superior. Com base nos pressupostos de análise de textos defendidos pelo ISD, desenvolvemos a análise de cinquenta (50) produções escritas, tidas como do gênero artigo de opinião, no momento em que o agente-produtor, a partir da base orientativa dada a partir da proposta de escrita em situação de vestibular.

A seleção dos textos trazidos como exemplos do corpus atende ao seguinte critério: a primeira produção contempla todas as fases da sequência 
argumentativa; a segunda, por sua vez, apresenta apenas parcialmente as fases das sequências argumentativa e explicativa, o que pode demonstrar diferentes estruturas tipológicas empreendidas por agentes-produtores diferentes, a partir do mesmo contexto e, são, sobretudo, exemplos do tipo mais recorrente da sequencialidade dos textos.

Para efetivar a análise, foram construídos símbolos para a identificação das fases das sequências argumentativa e explicativa. Para as fases da argumentativa, os critérios foram os de cores e as siglas. Em relação às cores:

\begin{tabular}{|l|l|}
\hline Cor do realce & Fases da sequência argumentativa \\
\hline ( CINZA $)$ & Tese \\
\hline$[$ AMARELO] & Argumento \\
\hline$\{$ LARANJA $\}$ & Contra-argumento \\
\hline$<$ AZUL $>$ & Conclusão \\
\hline
\end{tabular}

Em relação às siglas utilizadas para as sequências argumentativas:

\begin{tabular}{|l|l|}
\hline \multicolumn{1}{|c|}{ Itens analisados } & \multicolumn{1}{|c|}{$\begin{array}{c}\text { Identificação da Sequência } \\
\text { Argumentativa (SA) }\end{array}$} \\
\hline $\begin{array}{l}\text { SAC = Sequência Argumentativa } \\
\text { Completa }\end{array}$ & Presença de todas as fases da SA \\
\hline $\begin{array}{l}\text { SAP1 = Sequência Argumentativa } \\
\text { Parcial 1 }\end{array}$ & Ausência de uma das fases da SA \\
\hline $\begin{array}{l}\text { SAP2 = Sequência Argumentativa } \\
\text { Parcial 2 }\end{array}$ & Ausência de duas das fases da SA \\
\hline $\begin{array}{l}\text { SAP3 = Sequência Argumentativa } \\
\text { Parcial 3 }\end{array}$ & Ausência de três das fases da SA \\
\hline
\end{tabular}

Os mesmos critérios foram utilizados para as sequências explicativas: cores e siglas. Em relação às cores: 


\begin{tabular}{|l|l|}
\hline \multicolumn{1}{|c|}{ Cor da fonte } & \multicolumn{1}{c|}{$\begin{array}{c}\text { Fases da sequência explicativa } \\
\text { (SE) }\end{array}$} \\
\hline FONTE VERMELHA & Constatação Inicial (CI) \\
\hline FONTE ROXA & Problematização \\
\hline FONTE MARROM & $\begin{array}{l}\text { Resolução (explicação ou } \\
\text { justificativa) }\end{array}$ \\
\hline FONTE VERDE & Avaliação \\
\hline
\end{tabular}

Em relação às siglas:

\begin{tabular}{|l|l|}
\hline \multicolumn{1}{|c|}{ Itens analisados } & $\begin{array}{c}\text { Identificação das Sequências } \\
\text { Explicativas }\end{array}$ \\
\hline $\begin{array}{l}\text { SEC = Sequência Explicativa } \\
\text { Completa }\end{array}$ & Presença de todas as fases da SE \\
\hline $\begin{array}{l}\text { SEP1 = Sequência Explicativa } \\
\text { Parcial 1 }\end{array}$ & Ausência de uma das fases da SE \\
\hline $\begin{array}{l}\text { SEP2 = Sequência Explicativa } \\
\text { Parcial 2 }\end{array}$ & Ausência de duas das fases da SE \\
\hline $\begin{array}{l}\text { SEP3 = Sequência Explicativa } \\
\text { Parcial 3 }\end{array}$ & Ausência de três das fases da SE \\
\hline
\end{tabular}

\section{Análise da Sequencialidade dos Textos}

Conforme apresentado, analisamos a materialidade textual de produções textuais dos candidatos ao Vestibular da UFGD no ano de 2010, objetivando identificar como se efetivaram as capacidades discursivas, notadamente as sequências argumentativas e sequências explicativas utilizadas pelos candidatos. Iniciamos com a produção escrita 4 (número em relação ao corpus utilizado para análise). 
$\left(1^{\circ}\right)$ A percepção do ambiente através dos sentido é inerente aos animais, inclusive ao homem. Assim, da mesma forma que uma abelha é atraída pela beleza e pelo perfume da flor, nós, seres humanos, somos primeiramente fisgados pela beleza física do outro. TESE Entretanto, por trás de uma flor atraente, muitas vezes há uma planta carnívora. CONTRA-ARG Essa simples comparação ilustra um grande dilema da sociedade ocidental capitalista moderna: o jogo essência versus aparência. TESE NOVA

$\left(2^{\circ}\right)$ Durante o período de evolução da espécie humana, quando vivíamos a transição do nomadismo para o sedentarismo, não havia nenhum tipo de acúmulo ou propriedade, a beleza não existia num conceito. SE CI 1A proximidade com a natureza nos torna mais instintivos, biológicos e, portanto, a aparência possuía finalidade meramente reprodutiva. ARG 1 $\left(3^{\circ}\right)$ Mais tarde, no auge do Império grego, através da arte, dos esportes e da mitologia, a beleza adquiriu conceito. Em seu bojo, estavam a simetria, a sustentação, e o equilíbrio, relacionando-a à escultura e à arquitetura; a força, a saúde do corpo e da mente, relacionando-a aos jogos olímpicos, que exploravam habilidades diversas, a sabedoria, a experiência, a elevação, a pureza e o pudor, relacionando-a à mitologia. SE CI 2 $\left(4^{\circ}\right)$ Com o advento do capitalismo, porém, cada vez mais, a beleza perde esses valores. O corpo vincula-se à mercadoria e o consumo controla as relações entre as pessoas. ARG2 Como produtos, devemos chamar a atenção logo no primeiro instante, ter boa aparência, abominar qualquer falha ou defeito externo que possa comprometer a imagem positiva que o consumidor deve captar - não importa o que haja dentro da embalagem, atrás do rótulo ou sob o embrulho. SE CI3

$\left(5^{\circ}\right)$ Como mercadorias, devemos fazer parte de uma linha de montagem, devemos ser todos iguais.. SE CI 4Talvez seja por isso que o mundo vive em decadência moral: egoísmos, falsidade, vícios, depressão, insegurança, superficialidade. Agora, a beleza induz doenças como a anorexia e a bulimia, provoca desvios psicológicos, retarda o processo natural de envelhecimento (trazendo consigo o desrespeito aos idosos) gera crianças precoces e fúteis e induz à pedofilia através do cultivo de um padrão infantil de corpo. ARG 3

$\left(6^{\circ}\right)$ Somos animais, sim, mas possuímos algo que os outros não têm - a inteligência que nos torna críticos e nos permite avaliar com profundidade o ambiente a nossa volta. Por intermédio dela podemos escolher o que queremos individualmente e fazer valer nossa condição de racionais, não automáticos, nem instintivos. CONCLUSÃO 
Em se tratando das sequências, temos: a introdução vai de "A percepção" até "homem" em que o autor faz uma comparação existente entre os homens e os animais em relação à percepção do ambiente. A PREMISSA 1 (1 ${ }^{\circ}$ PARÁGRAFO) ocorre no enunciado que começa em "Assim" até "do outro" em que o vestibulando apresenta a premissa que vai servir de parâmetro para a tese que ele acredita ser a melhor opção. $\mathrm{O}$ contra-argumento é constituído pelo enunciado "Entretanto" até "carnívora", sustentando que as aparências podem enganar. A partir dessa reflexão, poderíamos dizer que existe uma TESE NOVA, implícita no final do $1^{\circ}$ PARÁGRAFO: "Essa simples" até "aparência" a fim de defender a proposição do dilema da sociedade moderna: essência ou aparência.

No $2^{\circ}$ PARÁGRAFO, de "Durante" até "reprodutiva", tem início a sequência explicativa/constatação inicial 1, para explicar que na transição do nomadismo para o sedentarismo o conceito de beleza não existia. No entanto, poder-se-ia considerar que de "A proximidade" até "reprodutiva" há uma fase argumentativa que justifica a premissa de instinto natural que nos faz priorizar o aspecto sensorial em detrimento a outros aspectos que formam a essência do ser humano. Podemos considerar que há um encaixamento na organização das sequências nesse $2^{\circ}$ PARÁGRAFO: ARGUMENTO: De "A proximidade" até "biológicos", Sequência Explicativa: De "Durante" até "reprodutiva"; e até a fase que vai de "Durante" até "conceito". Por fim, no último período, temos a conclusão.

No $3^{\circ}$ PARÁGRAFO, a segunda SEQUÊNCIA EXPLICATIVA/ CONSTATAÇÃO INICIAL2, de "Mais tarde" até "mitologia", o vestibulando descreve o surgimento do conceito de beleza, atribuída aos gregos que relacionavam a beleza à força física, saúde do corpo e da mente, associando esses elementos a modelos inspirados na mitologia. Aqui, da mesma forma que no $2^{\circ}$ parágrafo, temos a macroproposição da sequência explicativa e sequência narrativa.

No 4" PARÁGRAFO, de "Com o advento" até "pessoas", o agente-produtor utiliza a fase ARGUMENTATIVA reforçando a tese: o homem volta a ser dirigido pelos instintos naturais, seduzido pelo apelo comercial, aderindo ao consumismo. A SEQUÊNCIA EXPLICATIVA/ CONTATAÇÃO INICIAL 3 (SE CI 3) serve para explicar o processo pelo qual passa o homem para ser aceito pela sociedade. 
No início do 5\% PARÁGRAFO, de "Como mercadorias" até "todos iguais", continua a fase de SEQUÊNCIA EXPLICATIVA/ CONTATAÇÃO INICIAL 4, comparação da padronização da beleza a uma linha de montagem, como se fôssemos realmente uma peça fabricada em série.

No 5 PARÁGRAFO, de "talvez" até "corpo", entendemos que estão implícitos ARGUMENTOS que defendem a tese nova, quando optamos por dar prioridade à aparência, esquecendo-nos da essência, e, como consequência, o mundo enfrenta uma fase de decadência moral. A opção para alcançar o padrão de beleza imposto pelo sistema capitalista tem ocasionado sérios distúrbios alimentares, bem como a não aceitação do processo natural de envelhecimento e outros distúrbios psíquicos que oprimem o homem contemporâneo.

$\mathrm{Na}$ CONCLUSÃO, (6 ${ }^{\circ}$ PARÁGRAFO), o autor-empírico, sutilmente, convida o leitor a refletir sobre o fato de que, se somos dotados de inteligência, precisamos saber discernir o que é importante e fazer valer a nossa vontade, e não simplesmente aceitarmos o padrão imposto pela sociedade. Apresentamos a seguir o quadro que sistematiza o que foi descrito sobre a planificação da produção textual analisada. 


\section{Produção Textual 4}

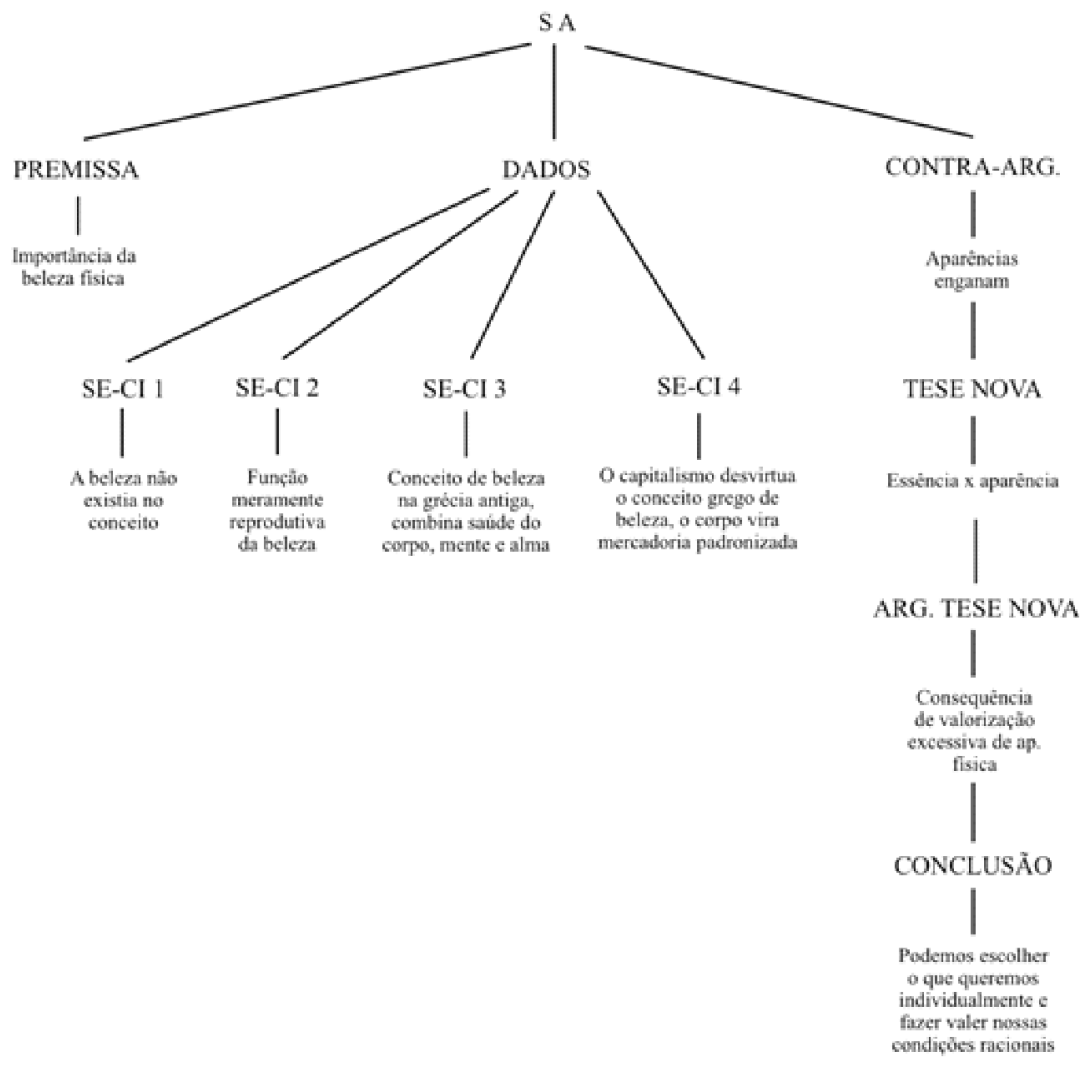

Figura 1 - Análise da produção escrita 4

Quanto à sequência argumentativa da primeira produção analisada, identificamos as quatro fases prototípicas- SAC (sequência argumentativa completa). Na sequência explicativa, constatamos apenas a utilização de apenas uma fase, sendo classificada como SEP3 (sequência explicativa parcial 3).

Passemos agora à análise da segunda produção escrita 7. 
$\left(1^{\circ}\right)$ Para mim, a definição de beleza está em constante mutação, porém, atualmente nos encontramos na fase onde o belo significa literalmente um corpo perfeito, cabelos perfeitos, pele perfeita e que a busca por esse ideal deve ser alcançada a qualquer preço; i.e., a "luta" para atingir esse estereótipo que torna homens e mulheres cada vez mais desfigurados. TESE 1

$\left(2^{\circ}\right)$ As mulheres, em sua maioria, permitem-se ser vítimas do paradigma da beleza sujeitando-se a grandes riscos e graves consequências. SE CI 1 A individualidade desaparece a cada instante; revistas estampam em suas capas "vista-se como...", “copie o cabelo..." e quase sem perceber, passamos a ser nada mais que bonecas em cama de hospital. ARG1

$\left(3^{\circ}\right)$ Vemos diariamente, principalmente na televisão, pseudo-celebridades que alcançam a fama somente por seus atributos físicos. ARG 2A mídia que ora defende a individualidade em um piscar de olhos é o carrasco, nos expondo ao paradigma de que as mulheres precisam somente da beleza - mesmo que artificial - como o único artifício para total realização.

$\left(4^{\circ}\right)$ Com essas influências externas passamos a confundir a boa aparência com ideal de beleza. Aprendemos a deixar a essência pessoal em segundo plano, quase intocada, esquecida. CONTRA-ARG Costumava pensar que a "gordinha bem resolvida" era uma máscara para fugir dos julgamentos da sociedade, após certa dose de discernimento, pude ver, de fato que a gordinha bem resolvida é muito mais feliz que a magra que se acha gorda. ARG DA TESE 2

$\left(5^{\circ}\right)$ Estamos ensinando aos pequenos que a aparência física substitui o caráter, que a saúde só deve ir ao encontro da busca pelo corpo perfeito. A quebra de paradigmas começa em pensamentos e atitudesCONCLUSÃOe Vinícius de Morais que me desculpe, mas beleza não é fundamental TESE 2

As sequências argumentativas e explicativas estão assim distribuídas: PREMISSA ( $1^{\circ}$ PARÁGRAFO) em que o agente-produtor defende que a beleza física perfeita deverá ser alcançada a qualquer preço. Ele afirma, com a SEQUÊNCIA EXPLICATIVA/CONSTATAÇÃO INICIAL, que a falta de discernimento na busca pela beleza perfeita acaba por desfigurar homens e mulheres por não entenderem o absurdo dessa busca radical pela beleza padrão. O agente deduz que as mulheres são as maiores vítimas da busca 
pela beleza perfeita, arriscando a vida. Em seguida, há dois argumentos para subsidiar a tese: busca pelo corpo perfeito.

No trecho do ARGUMENTO 1 (2 ${ }^{\circ}$ PARÁGRAFO), de “A individualidade" até "hospital", há o apelo da propaganda das revistas que ditam a moda do vestir-se e do corte de cabelo. O ARGUMENTO 2 ( $3^{\circ}$ PARÁGRAFO), que vai de "Vemos diariamente" até "atributos físicos", mostra a exploração de personagens televisivos que são contratados, via de regra, por atenderem ao padrão de beleza imposto pela sociedade. A partir desse segmento, o agente-produtor introduz um CONTRA-ARGUMENTO, destacando um ponto de vista que defende algo diferente da tese inicial.

No $3^{\circ}$ PARÁGRAFO, de "A mídia" até "esquecida", o agenteprodutor afirma que a mídia é responsável pela confusão de valores que as mulheres da atualidade enfrentam, porque, ao mesmo tempo em que se valoriza a individualidade, vende a ideia de que a aparência física é suficiente para que a mulher se realize, fazendo-a esquecer-se da importância de outros atributos como a honestidade, o respeito à cultura e individualidade do outro, a solidariedade, a caridade, a justiça, a verdade, o amor. A PREMISSA 2, no final do $5^{\circ}$ PARAGRAFO, (a beleza não é fundamental) é defendida no ARGUMENTO DA TESE 2 (PARÁGRAFO $4^{\circ}$ ), que vai de "Costumava" até "gorda", em que o agente-produtor reconhece seu erro ao dizer que houve tempo em que se pensava que não era possível uma pessoa ser gorda e dizer-se feliz, "bem resolvida". No entanto, afirma que chegou à conclusão de que a felicidade está em aceitar-se como é: valorização da essência pessoal. Há uma nova SEQUÊNCIA EXPLICATIVA no $5^{\circ}$ PARÁGRAFO: De "Estamos ensinando" até "corpo perfeito", em que se constata a existência de equívoco nos valores educacionais em vigor, ao valorizar a aparência física em detrimento do caráter e que o corpo só será considerado saudável quando estiver perfeito. A CONCLUSÃO no $5^{\circ}$ PARÁGRAFO: "A quebra" até "atitudes" aparece após um argumento de que a consciência de uma nova forma de pensar consiste em tomar atitude, em defender esse novo modo de pensar.

Assim, temos, em relação à sequência argumentativa as quatro fases prototípicas SAC (sequência argumentativa completa); quanto à sequência explicativa, identificamos aplicação de apenas uma fase, sendo classificada como SEP3 (sequência explicativa parcial 3). 
O raciocínio argumentativo desse candidato coincide com o protótipo de sequência argumentativa adotado/adaptada pelo ISD, isto é, introdução de uma premissa (busca do corpo perfeito a qualquer preço), argumentos dessa premissa (só consegue espaço em capas de revista e programas de televisão aqueles(as) que alcançam o padrão de beleza dominante); contra-argumento (a mídia, ao mesmo tempo em que defende a individualidade induz o leitor/telespectador a buscar o padrão de beleza ideal, correndo o risco de ficar deformado, fazendo com que todos (as mulheres principalmente) só se sintam realizados quando conseguem atingir esse ideal de beleza). Nova tese (beleza não é fundamental) que é precedida pelo argumento de que a felicidade está em aceitar-se fisicamente. Quando o agente reflete, como se estivesse confidenciando, que, "após certa dose de discernimento, podemos ver, de fato, que a gordinha bem resolvida é muito mais feliz que a magra que se acha gorda", entendemos que não se podem colocar as coisas passageiras no topo da hierarquia de valores, uma vez que, a partir da certeza de que a beleza física é efêmera e inconstante (depende de idade, biotipo, condições econômicas, padrão de beleza vigente na época e tempo em que se vive, entre outras variáveis), não é o requisito mais importante. A energia e interesse do indivíduo são canalizados para outras áreas da vida.

Quanto à utilização de apenas uma fase da sequência explicativa nas recorrências, não houve necessidade, principalmente pelo contexto (destinatário composto por professores com formação em Letras), de justificar e avaliar as constatações iniciais da sequência. Entendemos que existe limitação de espaço (30 linhas no máximo) no contexto de vestibular o que obriga o vestibulando a ser sucinto ao produzir o texto, o que pode ter contribuído para o candidato evitar a utilização de sequências explicativas mais elaboradas, com problematizações, desdobramentos e avaliações.

$\mathrm{O}$ quadro a seguir resume a infraestrutura utilizada pelo produtor do texto quanto às tipologias: 


\section{Produção textual 7}

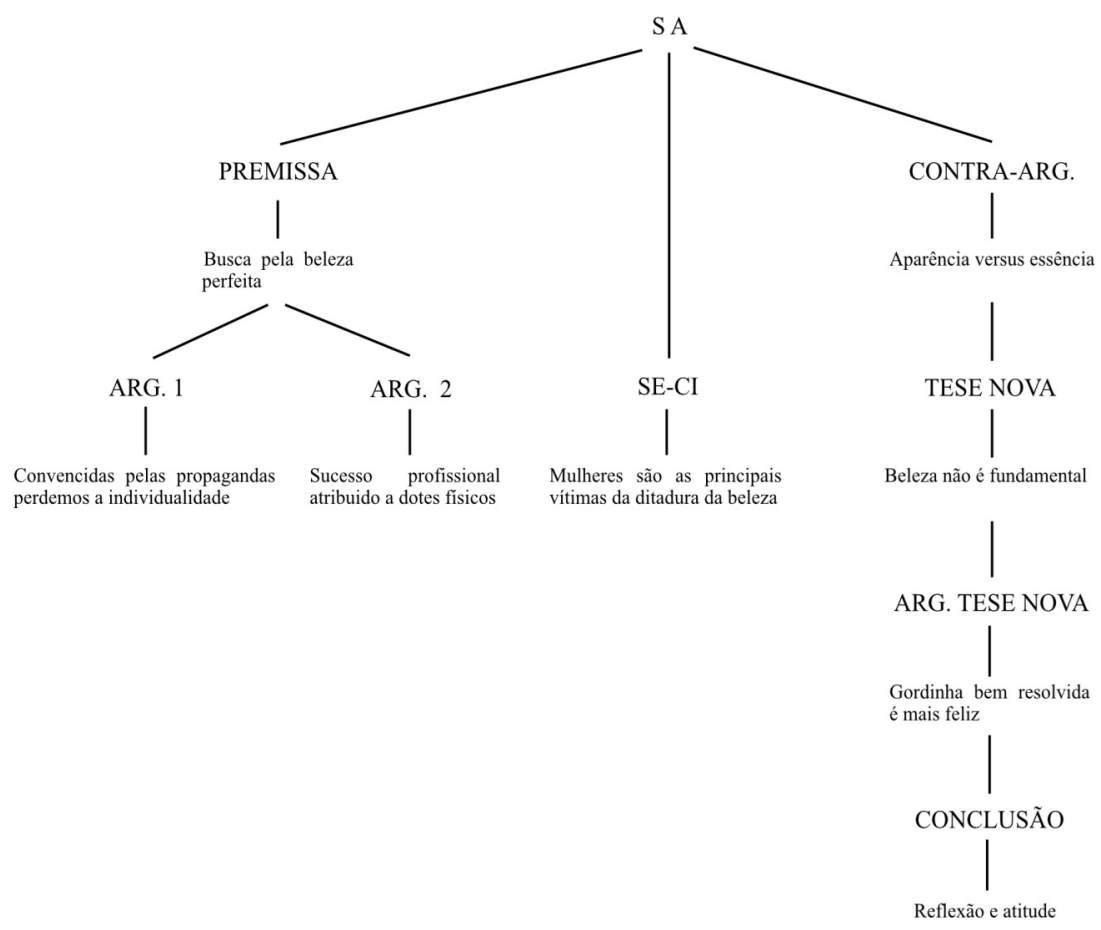

Figura 2 - Análise da produção escrita 7

\section{Interpretação dos Dados Gerados}

Concluídas as análises da organização sequencial do conteúdo temático, apresentamos os dados coletados do corpus de 50 produções escritas produzidas em situação de vestibular da UFGD, ano de 2010, das quais, por motivo de espaço, apresentamos apenas duas produções tidas como representativas. No gráfico de percentual de ocorrências de sequência argumentativa, obtivemos os seguintes números na classificação: do total de 50 produções, 27 textos possuem todas as fases da sequência argumentativa prototípica, por isso, são denominados de SAC (sequência argumentativa completa), 17 textos na classe SAP1 (ausência de uma das fases); 05 textos como SAP2 (ausência de duas das fases) e SAP3 (ausência de três das fases). 
No gráfico a seguir, visualizamos o percentual das ocorrências das sequências argumentativas:

\section{Ocorrências de Sequências Argumentativas}

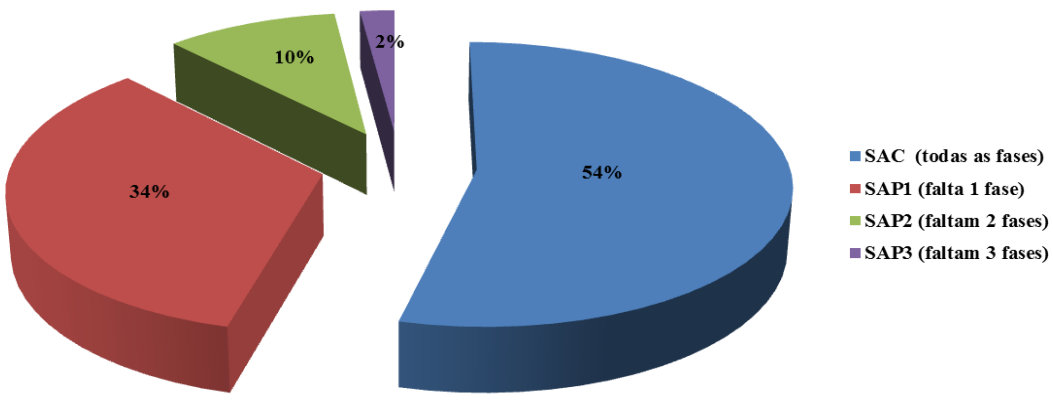

Gráfico 1 - Ocorrências das Sequências Argumentativas

O texto 04 , analisado anteriormente, elaborado com as quatro fases das sequências argumentativas, contribuiu para uma organização mais consistente do ponto de vista argumentativo. De nossa parte, acreditamos que a estrutura completa visa persuadir com mais eficácia o destinatário, por lançar mão das estratégias de argumentação e contra-argumentação. Lembramos que, dentre as estratégias retóricas do gênero artigo de opinião, temos a sustentação, refutação e negociação. Xavier ${ }^{10}$ (2006) aponta que a sequência completa é o padrão de textualização ideal para um aluno ingressante no Curso Superior.

Apresentamos a seguir o gráfico demonstrativo das ocorrências das sequências explicativas:

${ }^{10}$ Xavier chega a conclusões semelhantes às nossas, mas, neste caso, analisando produções escritas da Universidade Federal de Minas Gerais. 


\section{Ocorrências de Sequências Explicativas}

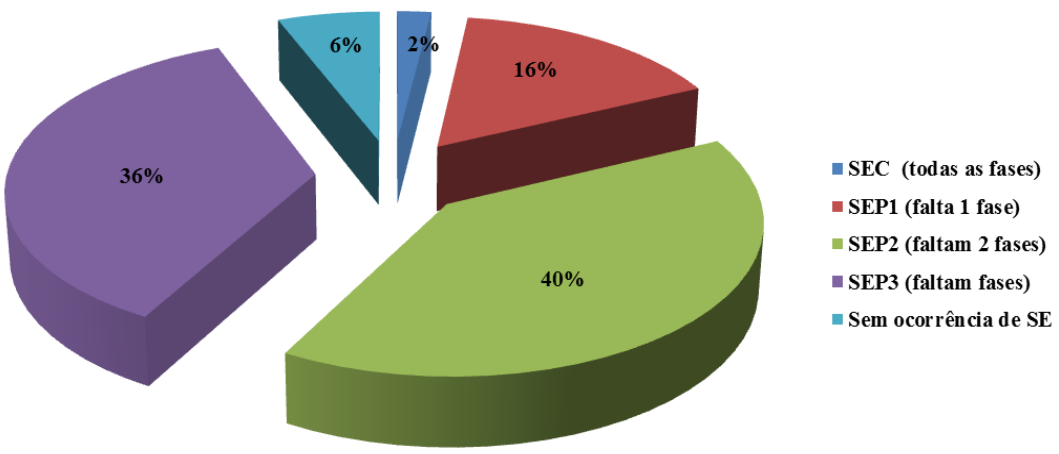

Gráfico 2 - Ocorrências de Sequências Explicativas

$\mathrm{Na}$ utilização das fases das sequências explicativas, obtivemos os seguintes dados: 01 texto foi considerado contemplado com todas as fases e denominado de SEC (sequência explicativa completa), 08 textos estão na classe SEP1 (ausência de uma das fases da SA); 20 textos como SEP2 (ausência de duas das fases da SE) e 18 textos classificados como SEP3 (ausência de três das fases da SE) e 3 das produções não apresentaram nenhuma das fases da SE.

Refletindo sobre a causa da ocorrência de apenas uma produção com a sequência explicativa completa, lançamos a hipótese de que o agente-produtor levou em consideração o contexto de vestibular, em que o interlocutor em potencial é um professor com formação em Letras, e que, pela bagagem sociocultural, não haveria necessidade de esmiuçar o tema em pauta, tido como de desenvolvimento fácil pelos candidatos; por isso, não problematizou, não justificou Sobretudo, o agente-produtor pode não ter empreendido a ação de escrever sequências explicativas, uma vez que não viu nenhuma constatação ou fenômeno incontestável que precisasse de explicações (BRONCKART, 2003). De fato, a proposta de produção de texto (o valor da beleza ao longo dos séculos) pode não ter se constituído como um fenômeno que necessitasse de desdobramentos. Entretanto, o agente-produtor deveria ter explicado as causas ou as razões de uma constatação inicial ou, ainda, enriquecê-la e, desse modo, estaria circunscrito nos limites de uma sequência explicativa. 


\section{Considerações Finais}

Em termos numéricos, pela análise das produções escritas, 54\% do corpus apresentou a organização sequencial prototípica. Quanto à sequência explicativa, a pesquisa revelou que a maioria dos agentes-produtores utilizou apenas 2 fases (40\%) ou 1 fase (36\%). Os 16\% que utilizaram 3 das fases da sequência explicativa aproximaram-se do modelo prototípico dessa sequência, juntamente com o único que conseguiu apresentar as fases completas da sequência explicativa.

Dentre as seis notas classificadas entre 8,0 a 10,00, quatro candidatos utilizaram sequência argumentativa completa (SAC) e dois candidatos utilizaram sequência argumentativa parcial 1 (SAP1); dentre as vinte notas classificadas entre 6,0 a 7,5, sete candidatos utilizaram SAC, nove candidatos utilizaram SAP1, três candidatos utilizaram SAP2 e um candidato utilizou SAP3; dentre as vinte e quatro notas classificadas entre 4,0 a 5,5, quatorze candidatos utilizaram SAC, nove candidatos utilizaram SAP1, um candidato utilizou SAP2 e nenhum candidato dessa faixa utilizou SAP3.

Neste contexto, ainda que as atribuições de valores não possam ser creditadas apenas à utilização das sequências tipológicas, já que existe uma grade de avaliação de textos que contemplam outros itens de leitura, podemos associar, ao menos parcialmente, a nota atribuída em relação à utilização das sequências prototípicas ou sequências parciais 1. A utilização prototípica, cremos, pode ser reflexo das produções escritas no gênero dissertação escolar. Em tal gênero são comuns as aulas de introdução (tópico frasal), desenvolvimento e conclusão. Consubstancia essa reflexão o fato de que boa parte dos inscritos no processo seletivo vestibular produziu um gênero híbrido entre o Artigo de Opinião e a Dissertação Escolar.

Ao retomar as discussões apresentadas, é necessário deixar claro que as sequências tipológicas não podem ser critérios de classificação/definição de uma prática social de linguagem, como também atestam Bronckart (2003) e Marcuschi (2003, p. 22). Para Bronckart (2003), todo texto empírico é constituído por um ou vários tipos de discursos amalgamados e planificados por uma ou por várias sequências. No entanto, afirma o autor que "os gêneros não podem ser diretamente definidos e classificados em função de suas características lingüísticas nele observáveis” (2003, p. 256). Para Marcuschi (2003), os gêneros textuais se constituem como ações sócio-discursivas para agir sobre o mundo e dizer o mundo, constituindo-o de algum modo. O 
autor afirma ainda que (2003, p. 29) "quando dominamos um gênero textual, não dominamos uma forma lingüística e sim uma forma de realizar lingüisticamente objetivos específicos em situações sociais particulares”. Necessário se faz esclarecer que os objetos de análise desta reflexão são as sequências tipológicas de Adam e adaptadas por Bronckart (2003); no entanto; o foco de pesquisa do Grupo de Genebra são os tipos psicológicos dos mundos discursivos, em que o autor apresenta os mundos discursivos associando-os às marcas linguísticas que retratam tais mundos e semiotizadas na língua natural do autor empírico.

Esse estudo considerou o uso dos elementos relativamente estáveis do gênero artigo de opinião, particularmente as sequências explicativa e argumentativa que explicitassem o ponto de vista dos candidatos em torno do tema beleza, com ênfase na sequencialidade dos enunciados. Nosso objetivo não foi o de simplesmente realizar um trabalho de classificação das teorias, mas sim interpretar e avaliar a eficácia das utilizações dos objetos de estudo: a análise da planificação das sequências prototípicas argumentativas e explicativas nas produções textuais dos vestibulandos.

Constatamos que o corpus estudado apresentou números relevantes de utilização de sequências argumentativas prototípicas e poderíamos considerar que, na média das avaliações, representaram ações de linguagem regulares do corpus. Em relação à identificação de apenas duas sequências explicativas completas, uma justificativa plausível é a de que o tema solicitado pela banca organizadora da prova não exigia esclarecimentos adicionais para a compreensão do enunciado, não comprometendo a qualidade da produção do texto. A nosso ver, as sequências tipológicas, elemento componente da infraestrutura, pode ter função heurística, tais como: auxiliar o docente no momento da leitura da produção do aluno, por exemplo, em situação vestibular $^{11}$.

Reconhecemos que a avaliação de uma produção escrita não pode se respaldar apenas na estrutura planificadora de planificação de sequências, pois a criação de qualquer texto coerente envolve outros itens complexos

${ }^{11}$ As sequências tipológicas podem se constituir como elementos importantes no momento de avaliação de textos dentro dos processos seletivos vestibulares das universidades, principalmente, no item coesão textual. Neste item, podemos ver as articulações entre as partes de uma sequência dentro de um determinado gênero de texto. 
de estrutura lógico-semântica-cognitiva, além do contexto de produção que irá conduzir o diálogo entre autor empírico e o leitor, dentre outros fatores, considerando que, na perspectiva do ISD, todo texto representa uma ação imputada a um agente, por um motivo e uma intenção e está situada em uma formação social identificável (BRONCKART, 2003, p. 13). No entanto, para além de as análises mostrarem aspectos da organização textual, conforme adiantou Bronckart (2003, p. 89 - grifos do autor)

... é no quadro do ensino da produção e/ou interpretação dos textos, [que] nossas proposições teóricas não deveriam ser utilizadas senão como instrumentos de análise dentre outros, capazes apenas de esclarecer alguns aspectos da organização textual.

Para finalizar, um fator relevante a ser considerado para futuras pesquisas é o de ter sempre em mente as três capacidades de linguagem no ensino/aprendizagem de produção textual: capacidades de ação (contexto de produção), capacidades discursivas (tipos de discurso, tipos de sequência, mobilização do conteúdo temático) e capacidades linguístico-discursivas (mecanismos de textualização, conexão, vozes e modalizações). No contexto deste artigo, centramo-nos apenas em uma das capacidades discursivas (tipos de sequência), mas, em contexto de ensino, é necessário desenvolver sequências de atividades que contemplem as outras capacidades supramencionadas.

\section{Referências}

BAKHTIN, M. / VOLOCHINOV, V. N. 1997. Marxismo e Filosofia da Linguagem. 8. ed. São Paulo: HUCITEC, 1997 [1929].

BARROS, E. M. D. Gestos de ensinar e de aprender gêneros textuais: a sequência didática como instrumento de mediação. 2012. Tese (Doutorado em Estudos da Linguagem) - Universidade Estadual de Londrina, Londrina. 2012.

BORTONI-RICARDO, S. M. O professor pesquisador: introdução à pesquisa qualitativa. São Paulo: Parábola, 2008. 
BRONCKART, J-P. Atividade de linguagem, textos e discursos: por um interacionismo sociodiscursivo. Tradução Anna Rachel Machado e Péricles Cunha. 2. ed. São Paulo: EDUC, 2003 [1999].

BRONCKART, J-P. Atividade de linguagem, discurso e desenvolvimento bumano. Tradução Anna Rachel Machado et al. Campinas: Mercado de Letras, 2006. (Organização de Anna Rachel Machado e Maria de Lourdes Mattencio).

FLICK, U. Uma introducão à pesquisa qualitativa. 2. ed. Porto Alegre: Bookman, 2004.

GONÇALVES, A. V. Gêneros textuais e reescrita: uma proposta de intervenção interativa. 2008. Tese (Doutorado em Linguística e Língua Portuguesa) - Universidade Estadual Paulista Júlio de Mesquita Filho, Araraquara. 2008.

GONÇALVES, A. V.; BARROS, E. M. D. Planejamento sequenciado da aprendizagem: modelos e sequências didáticas. Linguagem \& Ensino, Pelotas, v. 13, n. 1, p. 37-69, jan./jun. 2010.

MACHADO, A. R. O diário de leitura: a introdução de um novo instrumento na escola. São Paulo: Martins Fontes, 1998.

MACHADO, A. R. Colaboração e crítica: possíveis ações do linguista na atividade educacional. Veredas On Line - Ensino, Juiz de Fora, v. 11, n. 2, p. 22-40, 2007. Disponível: <wmw.ufff.br/revistaveredas/files/2009/12/ artigo021.pdf>. Acesso em: 12 maio 2012.

MACHADO, A. R. Uma experiência de assessoria docente e de elaboração de material didático para o ensino de produção de textos na universidade PUCSP. In: MACHADO, A. R; ABREU-TARDELLI, L. S.; CRISTOVÃO, V. L. L. (Orgs.). Linguagem e Educação: o ensino e a aprendizagem de gêneros textuais. São Paulo: Mercado de Letras, 2009. p. 153-172.

MARCUSCHI, L. A. Gêneros textuais: definição e funcionalidade. In: DIONÍSIO A. P.; MACHADO, A. R.; BEZERRA, M. (Orgs.). Gêneros textuais e ensino. Rio de Janeiro: Lucerna, 2003. p. 19-36. 
NASCIMENTO, E. L. A dupla semiotização dos objetos de ensinoaprendizagem: dos gestos didáticos fundadores aos gestos didáticos específicos. Signum - Estudos da Linguagem, Londrina, v. 14, n. 1, p. 421445, jul. 2011.

NIÉRI, J. S. A transposição didática do gênero dissertação escolar. 2011.

Dissertação (Mestrado em Linguística e Transculturalidade) Universidade Federal da Grande Dourados, Dourados. 2010.

PÉCORA, A.. Problemas de redação. 4. ed. São Paulo: Martins Fontes, 1992 [1983].

VYGOTSKY, L. S. Pensamento e linguagem. Tradução Jefferson Luiz Camargo. 3. ed. São Paulo: Martins Fontes, 1998 [1987].

XAVIER, J. R. O interacionismo sociodiscursivo em produção de texto no processo seletivo de vestibular. 2006. Dissertação (Mestrado em Estudos Linguísticos) - Universidade Federal de Minas Gerais, Belo Horizonte. 2006. Disponível em: <https://docs.google.com/viewer?a=v\&q=cache: pKXY_vmYc5AJ:www.bibliotecadigital.ufmg.br/dspace/bitstream/ handle/1843/ALDR-6VTJY9/joelma_xavier_diss.pdf?sequence $\%$ $3 \mathrm{D} 1+\% 22+\mathrm{O}+$ interacionismo + sociodiscursivo $+\mathrm{em}+\operatorname{produ} \%$ $\mathrm{C} 3 \% \mathrm{~A} 7 \% \mathrm{C} 3 \% \mathrm{~A} 3 \mathrm{o}+\mathrm{de}+$ texto + no + processo + seletivo + de + vestibular $\% 22 \& \mathrm{hl}=$ pt-BR\&gl= br\&pid=bl\&srcid= ADGEESjKIXz3d-mc8X4vou8PKfn4YA 5o13wsYZorbADbj_e4gvJ5h-moSEjZDIXYXv RhyHacffULoPz XQ0jV1ke8Ek1SAgsp 3eLhBIQ8n IRkF39sWZd2Jjk RUpHIAmdADcXEzNA-mjI\&sig=AHIEtbSzurUEMOj0UdES7dcLC 5JoS0o5rQ>. Acesso em: 1 jul. 2010. 